\title{
Prediction of doxorubicin sensitivity in gastric cancers based on a set of novel markers
}

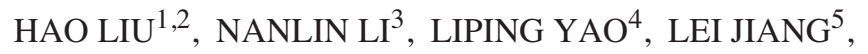 \\ GUOQIANG BAO ${ }^{1}$, JIPENG LI ${ }^{6}$, QINGJIU MA ${ }^{1}$ and ZHIGUO LIU ${ }^{4}$
}

\begin{abstract}
${ }^{1}$ Department of General Surgery, Tangdu Hospital, The Fourth Military Medical University, Xi'an; ${ }^{2}$ Department of General Surgery, School of Traditional Chinese Medicine, The Southern Medical University, Guangzhou; ${ }^{3}$ Department of Vascular and Endocrine Surgery and ${ }^{4}$ State Key Laboratory of Cancer Biology and Institute of Gastroenterology, Xijing Hospital, The Fourth Military Medical University, Xi'an; ${ }^{5}$ Department of Cardiovascular Surgery, The Medical School Hospital of Qingdao University, Qingdao; ${ }^{6}$ Department of General Surgery, Xijing Hospital, The Fourth Military Medical University, Xi'an, P.R. China
\end{abstract}

Received February 28, 2008; Accepted April 30, 2008

DOI: $10.3892 /$ or_00000097

\begin{abstract}
Chemotherapy is the standard treatment for patients with advanced gastric cancer; however, it has been difficult to predict chemotherapy response. In the current study, we attempted to develop a prediction model for individual response to doxorubicin chemotherapy in gastric cancer patients based on the hypothesis that expression analysis of a set of key drug sensitivity genes for doxorubicin could allow us to predict therapeutic response. From literature and our previous microarray data, the genes correlative in the expression levels with doxorubicin response were chosen. We selected seven reliable prediction markers for doxorubicin from 90 candidate sequences. Using expression data of genes quantified by real-time reverse transcription-PCR in 20 specimens, we fixed a linear model by multiple regressions, which converted the quantified expression data into a calculated inhibition rate of doxorubicin. Using the same set of genes, we then validated the formula in an independent set of 19 specimens. Our results suggest that the response of gastric cancer to doxorubicin can be predicted by expression patterns in this set of genes. The response prediction model will be of practical use to evaluate patient before chemotherapy.
\end{abstract}

\section{Introduction}

Gastric cancer ranks as the second leading cause of cancerrelated mortality worldwide (1). With early diagnosis,

Correspondence to: Dr Zhiguo Liu, State Key Laboratory of Cancer Biology and Institute of Gastroenterology, Xijing Hospital, The Fourth Military Medical University, Xi'an 710032, P.R. China E-mail: liuzhiguo@fmmu.edu.cn

Key words: doxorubicin, chemotherapy, gastric cancer, prediction, regression analysis gastrectomy with lymph node dissection results in a $>90 \%$ 5 -year survival rate, however, many cases are considered non-resectable at diagnosis because of locally advanced or metastatic disease. Chemotherapy then becomes one of the few treatment options. Doxorubicin and its derivatives are widely used in various chemotherapy regimens in combination with other chemicals. In a persective study, a regimen including epirubicin, cisplatin and fluorouracil improved the 5 -year survival rate among patients with advanced gastric adenocarcinoma from 23 to $36 \%$ (2). However, these regimens are not entirely satisfactory because mean average survival can only be extended $\sim 6$ months compared to best supportive care only (3). This poor therapy efficacy may be due to the fact that many gastric cancers are naturally resistant to many anticancer drugs, or acquire resistance during prolonged treatment. Therefore, predicting the occurrence of drug resistance becomes a major topic for successful chemotherapy of gastric cancers, unfortunately, to date, clinical tests for predicting cancer chemotherapy response are not available. Selecting an optimal regimen for each individual based on gene expression profile, or so-called personalized medicine has been proposed $(4,5)$. However, individual drug resistance related markers including $\mathrm{P}$ glycoprotein (P-gp) and multidrug resistance associated protein (MRP) have shown little predictive value (6).

Recently, using multiple genes or even microarray data to predict chemosensitivity has achieved some success in certain types of tumors though still lacks support from a large scaled clinical trial (7-11). However, various genetic events are involved in the mechanisms of drug sensitivity in different tumor types to different chemotherapy drugs, it would be important to know which gene set could be useful in predicting the doxorubicin response of gastric cancer in chemotherapy. In the current study, we selected multiple candidate genes based on previous gene profiling data, then a prediction model of doxorubicin response was developed by multiple regression analysis using selected genes and verified in gastric cancer specimens. 
Table I. The primer sets.

\begin{tabular}{|c|c|c|c|c|}
\hline Gene symbol & & Primer sequence & Position & Product length \\
\hline \multirow[t]{2}{*}{ CYR61 } & $\mathrm{F}$ & 5'-CCAGAAATGTATTGTTCAAAC-3' & 886 & 242 \\
\hline & $\mathrm{R}$ & 5'-TCACACTCAAACATCCAG-3' & 1,127 & \\
\hline \multirow[t]{2}{*}{ GNAI1 } & $\mathrm{F}$ & 5'-CCAGAGATTCAAAACCCCAAACC-3' & 72 & 83 \\
\hline & $\mathrm{R}$ & 5'-GCGGCTGTTCCTCACGAC-3' & 154 & \\
\hline \multirow[t]{2}{*}{ IFITM1 } & $\mathrm{F}$ & 5'-AAACAGCAGGAAATAGAAAC-3' & 1 & 163 \\
\hline & $\mathrm{R}$ & 5'-GGAAGTGTTGAGTGAAGG-3' & 163 & \\
\hline \multirow[t]{2}{*}{$\mathrm{G} 1 \mathrm{P} 2^{\mathrm{a}}$} & $\mathrm{F}$ & 5'-TGGTGGACAAATGCGACGAA-3' & 296 & 242 \\
\hline & $\mathrm{R}$ & 5'-CAGGCGCAGATTCATGAACA-3' & 537 & \\
\hline \multirow[t]{2}{*}{ ADAM22 } & $\mathrm{F}$ & 5'-TTGCTGTCCTCTGAATAC-3' & 407 & 217 \\
\hline & $\mathrm{R}$ & 5'-AATCCTCTTGAGTAGTGTC-3' & 623 & \\
\hline \multirow[t]{2}{*}{ SPHK1 } & $\mathrm{F}$ & 5'-CTCTGGTGGTCATGTCTG-3' & 935 & 152 \\
\hline & $\mathrm{R}$ & 5'-AGCATAATGGTTCAAGGAAG-3' & 1,086 & \\
\hline \multirow[t]{2}{*}{ FN1 } & $\mathrm{F}$ & 5'-TAACTGCGAGAGTAAACC-3' & 521 & 203 \\
\hline & $\mathrm{R}$ & 5'-TGTCACCAATCTTGTAGG-3' & 723 & \\
\hline
\end{tabular}

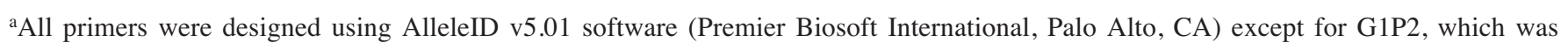
obtained from http://www.realtimeprimers.org/.

\section{Materials and methods}

Patients. Human specimens from surgically resected gastric cancers and corresponding clinical information were collected from three hospitals (Fourth Military Medical University, Southern Medical University and Qingdao University). A total of 45 samples (10 women and 25 men; median age, 65; range, 37-82 years) were selected for the study. All of the patients had histologically proven gastric cancer and had not received any treatment before tumor sampling. The patients were required to have no significant baseline laboratory abnormalities with performance status (WHO) 0-2. The study protocol was approved by the Human Ethics Review Committee of the Fourth Military Medical University and informed consent was obtained from the patients before the start of this study. The tumor specimens were randomly divided into two groups: training group and validation groups. The former was used as experimental samples to develop a prediction model and the latter was used to test samples to confirm the predictive accuracy of the developed model. Samples were cut into three pieces: one piece was HE-stained to histologically confirm the proportions of cancer cells in the specimens $>70 \%$, one was subjected for histoculture drug response assay (HDRA) and one was stored at $-80^{\circ} \mathrm{C}$ until real-time PCR analysis.

Histoculture drug response assay. HDRA was carried out following the protocol published previously (12). Briefly, the specimens were scissor-minced into pieces $\sim 0.5-\mathrm{mm}$ in diameter, which were then placed on each of the prepared collagen surfaces in 24-well plates. The plates were incubated for 7 days at $37^{\circ} \mathrm{C}$ with $15 \mu \mathrm{g} / \mathrm{ml}$ doxorubicin (Sigma, St. Louis, MO) dissolved in RPMI-1640 medium containing $20 \%$ FCS in a humidified atmosphere containing 95\% air and 5\% $\mathrm{CO}_{2}$. After histoculture, $100 \mu 1 \mathrm{HBSS}$ containing $0.1 \mathrm{mg} / \mathrm{ml}$ collagenase (type I, Sigma) and $100 \mu \mathrm{l}$ $5 \mathrm{mg} / \mathrm{ml}$ MTT (Sigma) solution were added to each well and incubated for another $8 \mathrm{~h}$. After extraction with DMSO, the absorbance of the solution in each well was read at $540 \mathrm{~nm}$. The absorbance/g of histocultured tumor tissue was calculated from the mean absorbance of tissue from four culture wells and tumor-tissue weight determined prior to culture. The inhibition rate was calculated using the formula: Inhibition rate $(\%)=(1-$ mean absorbance of treated tumor/g/mean absorbance of control tumor/g) x 100 .

cDNA preparation. RNA isolation and reverse transcription was performed within one week of storage at $-80^{\circ} \mathrm{C}$. The smashed tissue samples were lysed with TRIzol Reagent (Invitrogen, Carlsbad, CA) and RNA was isolated following the manufacturer's protocol. RNA quality from each sample was assessed by visualization of the $28 \mathrm{~S} / 18 \mathrm{~S}$ ribosomal RNA ratio. Total RNA $(2 \mu \mathrm{g})$ extracted from tumor specimens was reverse transcribed using random hexamer and Superscript II (Invitrogen) according to manufacturer's protocol.

Real-time reverse transcription-PCR. Aliquot of the cDNA (equivalent to $10 \mathrm{ng}$ total RNA) was subjected to real-time reverse transcription-PCR (RT-PCR). The primer sets are supplied in Table I. Each reaction was carried out in triplicate using a DNA Engine Opticon2 system (Bio-Rad, Hercules, $\mathrm{CA}$ ) according to the manufacturer's instructions. Briefly, the $\mathrm{PCR}$ reaction was carried out in a $10 \mu \mathrm{l}$ final volume containing the following: $5 \mu 12$ X SYBR-Green I master mix (Qiagen, Valencia, CA), $0.5 \mu 110 \mu \mathrm{M}$ forward primer and reverse primer; and $1.0 \mu \mathrm{l}$ diluted cDNA and $3 \mu \mathrm{l}$ water. After an initial denaturation step at $95^{\circ} \mathrm{C}$ for $5 \mathrm{~min}$, temperature cycling was initiated. Each cycle consisted of denaturation at $94^{\circ} \mathrm{C}$ for $10 \mathrm{sec}$, annealing at $55^{\circ} \mathrm{C}$ for $15 \mathrm{sec}$ and elongation at $72^{\circ} \mathrm{C}$ for $15 \mathrm{sec}$. A total of 40 cycles were performed. These 
Table II. Differentially expressed sequences in doxorubicin-resistant cell lines.

\begin{tabular}{|c|c|c|c|c|c|}
\hline Gene symbol & Accession & Gene symbol & Accession & Gene symbol & Accession \\
\hline $\mathrm{ABCB} 1$ & AA135957 & ERBB3 & AA877334 & OLR1 & AA682386 \\
\hline ACAT2 & $\mathrm{R} 25823$ & FLJ12953 & R39223 & PALM2-AKAP2 & AA488418 \\
\hline \multirow[t]{2}{*}{ ADAM22 } & AA461474 & FLJ31340 & AA644099 & PAX6 & R95962 \\
\hline & N29801 & FN1 & AA953560 & PCOLCE & AA513387 \\
\hline ALDH1B1 & AA702358 & & N73836 & & AA670200 \\
\hline \multirow[t]{2}{*}{ ARFGEF2 } & AA099582 & G1P2 & AA120862 & PELI1 & W86504 \\
\hline & AI961669 & GBP1 & AA280278 & PHTF2 & AA284466 \\
\hline ASK & AI952661 & & AA486849 & & AI017873 \\
\hline BEAN & R11384 & GBP2 & W01896 & & AI095488 \\
\hline $\mathrm{BF}$ & AA401441 & & W72748 & & AI821373 \\
\hline C19orf32 & AA443936 & GNAI1 & AI140462 & & R14908 \\
\hline C2orf33 & W74362 & & AW072795 & PJA1 & AA779217 \\
\hline C7orf23 & W48646 & & W46769 & PLAC8 & AA150254 \\
\hline CDH5 & T53625 & GSS & AA463458 & POLG2 & AI023804 \\
\hline CES2 & AI955681 & HABP4 & AA425398 & PPGB & AA916327 \\
\hline CLECSF2 & H11732 & HLA-E & R94660 & RAD21 & AA683102 \\
\hline \multirow[t]{2}{*}{ COL5A2 } & AA599273 & & AA703079 & RG9MTD2 & AA987337 \\
\hline & AA857098 & & AA988615 & SDBCAG84 & AA457092 \\
\hline \multirow[t]{2}{*}{ CROT } & AA043550 & HMG20B & AA775743 & & AI961469 \\
\hline & W84716 & HSD17B2 & AA970760 & SH3KBP1 & AA989257 \\
\hline CRYZ & R13434 & IFITM1 & AA058323 & SPHK1 & AI341901 \\
\hline CYR61 & AA012892 & ITPR1 & AA035450 & SRI & H60859 \\
\hline DDX58 & N29630 & LEPREL1 & AA894672 & STCH & H85311 \\
\hline DHRS8 & AI220736 & & AA894672 & STX11 & AA884281 \\
\hline DMTF1 & AA129860 & MCFP & AA465188 & TFRC & AA677486 \\
\hline DOCK11 & AA490315 & MGC2574 & AA777656 & & N21329 \\
\hline \multirow[t]{2}{*}{ DPP9 } & AA007308 & NCL & AA433818 & TGFB2 & AA176249 \\
\hline & AA011400 & NOD27 & AI016022 & TNFAIP3 & AA053239 \\
\hline EPLIN & AA487557 & NPC1 & AA634267 & TPBG & AA425666 \\
\hline EPS8L3 & AA134985 & NPC2 & AA630449 & UBR1 & AA665730 \\
\hline
\end{tabular}

triplicate measurements were averaged and relative gene expression levels were calculated as a ratio to $\beta$-actin expression level.

Statistics. For identifying prediction candidate genes, the PAM package v.2.1 for EXCEL was used, as described previously (13). Multiple regression analysis was carried out by NLReg software v.6.2 (Brentwood, TN). Statistical analyses comparing two groups were performed using SPSS11.0 software (Chicago, IL). Probability of $<0.05$ was considered statistically significant.

\section{Results}

Identifying prediction gene candidates from microarray data. To identify discriminatory genes for predicting sensitivity to doxorubicin, we obtained two sets of gene expression profiles of closely related drug-resistant and drug-sensitive gastric cancer cell lines. The EPG-257P and its doxorubicin-resistant variant EPG-257RDB described by Lage and Gyorffy was obtained from the Stanford Microarray Database (http:// genome-www5.stanford.edu) $(7,14)$. Microarray data for our previously established SGC7901 and SGC-7901/ADR was from unpublished results using a human genome 70-mer oligonucleotide microarray (CapitalBio Corporation, Beijing, P.R. China) (15). We compared the expression patterns of the doxorubicin-resistant cell lines to the parental cell lines. Since the RNA from EPG-257RDB was prepared from daunorubicin treated cells and SGC-7901/ADR from untreated cells, the significant changes were defined as 5- and 2-fold, respectively. In all, 10144 and 471 sequences were found to be differentially expressed (data not shown). To select discriminatory genes, we compared these two sets of resistance-associated genes. Ninety sequences were found to have similar changes in both sets, among them, all except one gene (PJA-1) was upregulated in resistant cells (Table II).

To select the most potent prediction marker genes from such a large number of candidates, we further verified this set 
Table III. Selected prediction marker gene candidates.

\begin{tabular}{|c|c|c|c|c|c|}
\hline Gene symbol & Gene name & Ref Seq & Locuslink ID & $\begin{array}{l}\text { EPG-257: } \\
\text { EPG-257RDB } \\
\text { ratio }\end{array}$ & $\begin{array}{l}\text { SGC-7901: } \\
\text { SGC-7901/ADR } \\
\text { ratio }\end{array}$ \\
\hline ADAM22 & $\begin{array}{l}\text { A disintegrin and } \\
\text { metalloproteinase } \\
\text { domain } 22\end{array}$ & $\begin{array}{l}\text { NM_016351 } \\
\text { NM_021722 } \\
\text { NM_021723 }\end{array}$ & 53616 & 0.1878 & 0.0823 \\
\hline CYR61 & $\begin{array}{l}\text { Cysteine-rich, } \\
\text { angiogenic inducer, } 61\end{array}$ & NM_001554 & 3491 & 0.1311 & 0.4952 \\
\hline IFITM1 & $\begin{array}{l}\text { Interferon induced } \\
\text { transmembrane } \\
\text { protein } 1(9-27)\end{array}$ & NM_003641 & 8519 & 0.1850 & 0.4617 \\
\hline FN1 & Fibronectin 1 & $\begin{array}{l}\text { NM_212474 } \\
\text { NM_212475 } \\
\text { NM_212482 } \\
\text { NM_212476 } \\
\text { NM_002026 } \\
\text { NM_212478 }\end{array}$ & 2335 & 0.1089 & 0.1984 \\
\hline SPHK1 & Sphingosine kinase 1 & $\begin{array}{l}\text { NM_182965 } \\
\text { NM_021972 }\end{array}$ & 8877 & 0.0753 & 0.3314 \\
\hline G1P2 & $\begin{array}{l}\text { Interferon, } \alpha \text {-inducible } \\
\text { protein (clone IFI-15K) }\end{array}$ & NM_005101 & 9636 & 0.1421 & 0.3326 \\
\hline GNAI1 & $\begin{array}{l}\text { Guanine nucleotide } \\
\text { binding protein (G protein), } \\
\alpha \text { inhibiting activity } \\
\text { polypeptide } 1\end{array}$ & NM_002069 & 2770 & 0.1699 & 0.2334 \\
\hline
\end{tabular}

of genes using the expression profiles of a previously defined group of clinical specimens of gastric cancer described by Chen et al (16). The data were obtained also from the Stanford Microarray Database. Only patients at stage III and IV were included in the evaluation since chemotherapy regimens containing doxorubicin were most common treatment options only for advanced gastric cancer patients and the staging factor has been well known as an independent prediction factor for survival. Among these patients, 15 with the longest survival time were regarded as chemotherapy sensitive cases, while 16 with the shortest survival time were regarded as resistant ones. The Prediction Analysis for Microarrays (PAM) training analysis was performed at thresholds 0.9. Centroid plots for the top seven genes associated with doxorubicin sensitivity are shown in Fig. 1 and Table III. Though ABCB1 has been shown to be overexpressed in both the study of Gyorffy et al and our data, it fails to produce a significant correlation with this set of clinical data.

Developing a doxorubicin response prediction model on gastric cancer specimens. The doxorubicin response was obtained using Histoculture Drug Response Assay (Table IV) (12). In 23 gastric cancer specimens, 20 produced evaluable results, three cases were eliminated due to contamination or

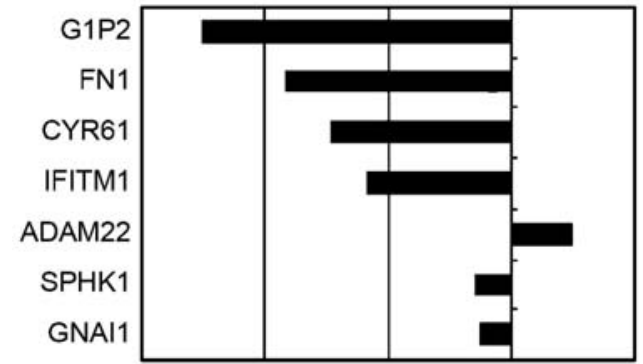

Figure 1. Centroid plot showing the top seven clones with highest potential on doxorubicin sensitive groups after shrinkage with threshold 0.8. Gene names are shown.

low absorbance of extracted formazan of the control tumor. The seven selected genes were subjected to real-time RT-PCR analysis for quantified expression on 20 gastric cancer specimens in training group to confirm correlation with doxorubicin response. Using expression data of selected seven candidate genes quantified by real-time RT-PCR, we performed multiple regression analysis using NLReg software to compose prediction models for the in vitro activity of doxorubicin. As shown in Table IV and Fig. 2, the 
Table IV. Comparison of clinical and pathological characteristics between the training and validation groups.

\begin{tabular}{|c|c|c|}
\hline Clinical and pathological factors & Training group $(n=20)$ & Validation group $(n=19)$ \\
\hline Age $^{a}$ & $61.45 \pm 11.58$ & $63.32 \pm 13.59$ \\
\hline \multicolumn{3}{|l|}{$\operatorname{Sex}^{b}$} \\
\hline Male & 11 & 12 \\
\hline Female & 9 & 7 \\
\hline \multicolumn{3}{|l|}{ Stage $e^{b}$} \\
\hline $\mathrm{I}+\mathrm{II}$ & 6 & 9 \\
\hline III+IV & 14 & 10 \\
\hline \multicolumn{3}{|l|}{ Tumor site ${ }^{b}$} \\
\hline Antrum & 13 & 9 \\
\hline Cardia & 4 & 7 \\
\hline Body & 3 & 3 \\
\hline \multicolumn{3}{|l|}{ Histology $y^{b}$} \\
\hline Intestinal & 14 & 15 \\
\hline Diffused & 2 & 3 \\
\hline Mixed & 4 & 2 \\
\hline Doxorubicin response ${ }^{c}$ & $34.65(12.7-89.2)$ & $32.50(15.0-80.3)$ \\
\hline
\end{tabular}

${ }^{a}$ Data are shown as mean \pm SD. There was no significant difference between the training and validation groups. ${ }^{b}$ Data are shown as number of cases. Not significant by $\chi^{2}$ test. ${ }^{c}$ Data are shown as median (range). Not significant by Mann-Whitney's U test.

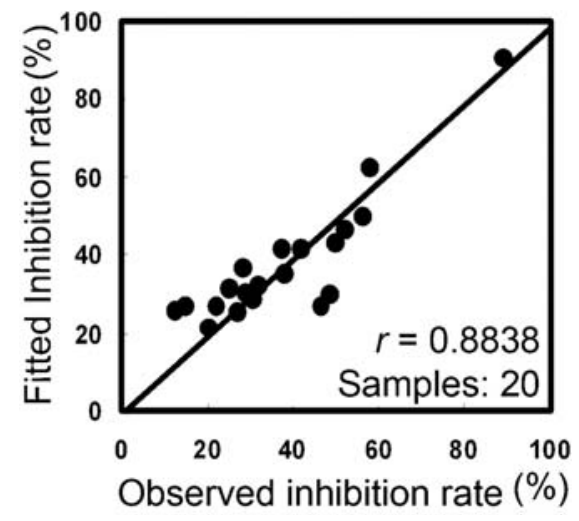

Figure 2. Prediction model for in vitro doxorubicin response. Using multiple regression analysis, we developed formulae to predict the response to doxorubicin using the variable expression data of selected marker genes. $\operatorname{Ln}[$ inhibition rate] $=3.967 * \operatorname{Ln}[$ ADAM22] $-3.981 * \operatorname{Ln}[$ CYR61] $+0.453 *$ $\mathrm{Ln}[\mathrm{FN} 1]-1.459 * \operatorname{Ln}[\mathrm{SPHK} 1]+0.983 * \operatorname{Ln}[\mathrm{GNI} 1]+3.076$ (gene names inside brackets indicate the expression level of indicated genes).

observed correlation coefficient indicated potent predictive values of the fixed formula. The NLReg analysis provides estimated $\theta p$ with $\mathrm{P}$, where a lower $\mathrm{P}$ indicates a lower probability for the observation that $\theta p$ could be 0 in the formula. A positive $\theta$ indicates that the corresponding explanatory variable acts as a positive factor in the formula, while a negative one indicates the inverse. The levels of $\theta$ do not directly account for the importance of the variable. IFITM1 and G1P2 were eliminated from the final formula since the estimated $\mathrm{P}$ for each $\theta p$ was much higher than those of the others.

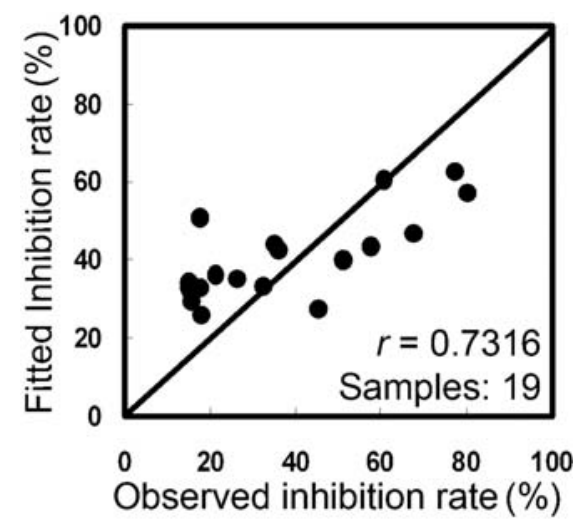

Figure 3. Validation of the prediction model for in vitro doxorubicin response. Using an independent set of data, the prediction model was validated in 19 gastric cancer specimens.

Validation of prediction model. To confirm the prediction accuracy of the fixed formula, the prediction model was validated in a validation set of gastric cancer specimens in the same way using the same genes. Twenty-two cases of gastric cancer specimens were collected. Three samples were eliminated and the 19 cases left were subjected to real-time RT-PCR analysis to quantify the expression levels of five selected marker genes and doxorubicin response was also tested using Histoculture Drug Response Assay (Table IV). Despite of the limited number of samples, the results showed that the current prediction model reliably predicted the response of cancer specimens to doxorubicin ( $r=0.73$, Fig. 3). 


\section{Discussion}

In this study, we selected seven marker genes by comparing microarray data from drug-resistant cell lines and subsequent PAM analysis, then determined expression data of the selected genes by real-time RT-PCR. By examining the variable expression levels of the component genes, the efficacy of doxorubicin was predicted using multiple regression analysis. Two more maker genes were eliminated at following expression data regression analysis. To avoid the possible artificial bias, we further validated the model in an independent set of samples. Although the functional significance of these novel markers in drug sensitivity is poorly understood, their expression levels were shown to be correlative with cellular sensitivity to doxorubicin in vitro.

Our study provided five novel genes for doxorubicin response prediction, including ADAM22, CYR61, FN1, SPHK1 and GNAI1. Among them, ADAM22 is a membraneanchored protein involved in cell-cell and cell-matrix interactions (17). CYR61 encodes a secreted, cysteine-rich, heparin-binding protein promoting the adhesion of endothelial cells through integrin and augments growth factor-induced DNA synthesis (18). FN1 is a glycoprotein involved in cell adhesion and migration process (19). SPHK1, a kinase that catalyzes the phosphorylation of sphingosine, may be necessary for the maintenance of tumor cell growth (20). GNAI1 is an $\alpha$-subunit of heterotrimetric $G$ protein, which is involved as modulator in various transmembrane signaling systems (21). Their functions remain largely unknown, but various results suggest their possible roles in drug sensitivity: FN1 has been implied to be a potent predictor for platinum resistance in ovarian cancer (22). SPHK1 (sphingosine kinase) was reported to be overexpress in chemotherapyresistant prostate cancer and leukemia cell line, and may be involved in regulating the sensitivity of Dictyostelium discoideum cells to cisplatin (23-28). Cells expressing sphingosin-1-phosphate lyase showed an increase in sensitivity to doxorubicin, which supports our findings (26).

In our study, several previously well-known drug-resistance genes including $\mathrm{ABCB} 1$ failed to be selected as one of predictors possibly due to the fact that $\mathrm{ABCB} 1$ is more likely to achieve overexpression in patients with multiple chemotherapies. Di et al reported that tumors acquired rapid increase in the expression of ABCB1 within days of the start of treatment (29). We have not verified this prediction model in patients with multiple chemotherapies. Current enrolled patients will be continually followed up to achieve data after multiple chemotherapies.

This is the first attempt to use expression profiling data for doxorubicin response prediction in fresh gastric cancer samples. Tanaka et al proposed that $\mathrm{ABCB} 1$ and TOP2A as doxorubicin sensitivity prediction factors, however these two genes have only been tested in cultured cells (8). Gyorffy et al also tried to link gene expression levels to doxorubicin responses with chemosensitivity in breast cancer (7). However, the proposed 79 genes associated with doxorubicin resistance did not overlap with our five suggested predictors, possibly because of the dramatic difference in genetic background between breast and stomach. In gastric cancer, progress on the prediction model of 5-fluorouracil has been achieved recently using microarray data. A 'Response index' system has been proposed by Matsuyama et al, which consists of TNFRSF1B, SLC35F5 and OPRT (30). However, the main obstacle lies in that many studies were restricted within cultured cell lines or limited patient cases (31), the significance of such prediction models need to be further verified on a larger scale.

Recently, much attention has been focused on microarray as a tool of the molecular prediction of drug response and survival. Profiling of gene expression patterns on genome-wide microarrays enables investigators to perform comprehensive analyses of abnormal molecular events in cancer cells. Several hopeful results have been published in various tumor types including leukemia, and ovarian cancer (7,32-34), however, due to the high cost of microarray and uncertain importance to patients survival, models with a few sensitivity predictors selected on microarrays might be more applicable in clinical practice $(11,35,36)$. Our prediction model may have some advantages in the prediction of drug response, such as low cost, easy to standardize and short time durance. However, the key issue to determine the possible clinical application lies in the prediction accuracy. This will call for further validation on a larger scale.

Various methods have been used to test the in vitro sensitivity of chemotherapy drugs $(37,38)$. We chose to use HDRA due to the fact that the HDRA allows tumor cells to maintain their native three-dimensional tissue architecture and viability longer than the cell suspension assay. Chemosensitivity determined by HDRA correlated well to clinical response (39). In our study, the HDRA demonstrated a high rate of evaluability $(86.7 \%)$. However, overall sensitivity of doxorubicin by HDRA is not satisfactory in gastric cancer specimens, $\sim 30.4 \%$ (11/39) in our study. The poor response rate is consistent with those previously reported (12). Giving the fact that doxorubicin still remains a common therapy option in chemotherapy regimens of gastric cancer patients; the low response rate of gastric cancer to doxorubicin should call the attention of clinicians. The response prediction model will be of practical use to evaluate the patient before chemotherapy.

\section{Acknowledgements}

This study was funded by the grants 30400016 and 30672369 from the National Natural Science Foundation of P.R. China.

\section{References}

1. Kelley JR and Duggan JM: Gastric cancer epidemiology and risk factors. J Clin Epidemiol 56: 1-9, 2003.

2. Cunningham D, Allum WH, Stenning SP, Thompson JN, Van de Velde CJ, Nicolson M, Scarffe JH, Lofts FJ, Falk SJ, Iveson TJ, Smith DB, Langley RE, Verma M, Weeden S, Chua YJ and Magic TP: Perioperative chemotherapy versus surgery alone for resectable gastroesophageal cancer. N Engl J Med 355: 11-20, 2006.

3. Wagner AD, Grothe W, Haerting J, Kleber G, Grothey A and Fleig WE: Chemotherapy in advanced gastric cancer: a systematic review and meta-analysis based on aggregate data. J Clin Oncol 24: 2903-2909, 2006.

4. Evans WE and Relling MV: Pharmacogenomics: translating functional genomics into rational therapeutics. Science 286: 487-491, 1999. 
5. Marsh S and McLeod HL: Cancer pharmacogenetics. Br J Cancer 90: 8-11, 2004.

6. van der Zee AG, Hollema H, Suurmeijer AJ, Krans M, Sluiter WJ, Willemse PH, Aalders JG and de Vries EG: Value of P-glycoprotein, glutathione S-transferase pi, c-erbB-2, and p53 as prognostic factors in ovarian carcinomas. J Clin Oncol 13: 70-78, 1995.

7. Gyorffy B, Serra V, Jurchott K, bdul-Ghani R, Garber M, Stein U, Petersen I, Lage H, Dietel M and Schafer R: Prediction of doxorubicin sensitivity in breast tumors based on gene expression profiles of drug-resistant cell lines correlates with patient survival. Oncogene 24: 7542-7551, 2005.

8. Tanaka T, Tanimoto K, Otani K, Satoh K, Ohtaki M, Yoshida K, Toge T, Yahata H, Tanaka S, Chayama K, Okazaki Y, Hayashizaki Y, Hiyama K and Nishiyama M: Concise prediction models of anticancer efficacy of 8 drugs using expression data from 12 selected genes. Int J Cancer 111: 617-626, 2004.

9. Komatsu M, Hiyama K, Tanimoto K, Yunokawa M, Otani K, Ohtaki M, Hiyama E, Kigawa J, Ohwada M, Suzuki M, Nagai N, Kudo Y and Nishiyama M: Prediction of individual response to platinum/paclitaxel combination using novel marker genes in ovarian cancers. Mol Cancer Ther 5: 767-775, 2006.

10. Terashima M, Fujiwara H, Takagane A, Abe K, Irinoda T, Nakaya T, Yonezawa H, Oyama K, Saito K, Kanzaki N, Ohtani S, Nemoto T, Hoshino Y, Kogure M and Gotoh M: Prediction of sensitivity to fluoropyrimidines by metabolic and target enzyme activities in gastric cancer. Gastric Cancer 6 (Suppl 1): 71-81, 2003.

11. Takata R, Katagiri T, Kanehira M, Tsunoda T, Shuin T, Miki T, Namiki M, Kohri K, Matsushita Y, Fujioka T and Nakamura Y: Predicting response to methotrexate, vinblastine, doxorubicin, and cisplatin neoadjuvant chemotherapy for bladder cancers through genome-wide gene expression profiling. Clin Cancer Res 11: 2625-2636, 2005

12. Furukawa T, Kubota T and Hoffman RM: Clinical applications of the histoculture drug response assay. Clin Cancer Res 1: 305-311, 1995.

13. Tibshirani R, Hastie T, Narasimhan B and Chu G: Diagnosis of multiple cancer types by shrunken centroids of gene expression. Proc Natl Acad Sci USA 99: 6567-6572, 2002.

14. Lage H, Jordan A, Scholz R and Dietel M: Thermosensitivity of multidrug-resistant human gastric and pancreatic carcinoma cells. Int J Hyperther 16: 291-303, 2000.

15. Ning H, Li T, Zhao L, Li T, Li J, Liu J, Liu Z and Fan D: TRF2 promotes multidrug resistance in gastric cancer cells. Cancer Biol Ther 5: 950-956, 2006.

16. Chen X, Leung SY, Yuen ST, Chu KM, Ji J, Li R, Chan AS, Law S, Troyanskaya OG, Wong J, So S, Botstein D and Brown PO: Variation in gene expression patterns in human gastric cancers. Mol Biol Cell 14: 3208-3215, 2003.

17. Zhu P, Sang Y, Xu H, Zhao J, Xu R, Sun Y, Xu T, Wang X, Chen L, Feng H, Li C and Zhao S: ADAM22 plays an important role in cell adhesion and spreading with the assistance of 14-3-3. Biochem Biophys Res Commun 331: 938-946, 2005.

18. Babic AM, Kireeva ML, Kolesnikova TV and Lau LF: CYR61, a product of a growth factor-inducible immediate early gene, promotes angiogenesis and tumor growth. Proc Natl Acad Sci USA 95: 6355-6360, 1998.

19. Main AL, Harvey TS, Baron M, Boyd J and Campbell ID: The three-dimensional structure of the tenth type III module of fibronectin: an insight into RGD-mediated interactions. Cell 71: 671-678, 1992.

20. Nava VE, Hobson JP, Murthy S, Milstien S and Spiegel S: Sphingosine kinase type 1 promotes estrogen-dependent tumorigenesis of breast cancer MCF-7 cells. Exp Cell Res 281: $115-127,2002$.

21. Wettschureck N and Offermanns S: Mammalian G proteins and their cell type specific functions. Physiol Rev 85: 1159-1204, 2005.

22. Helleman J, Jansen MP, Span PN, van Staveren IL, Massuger LF, Meijer-van Gelder ME, Sweep FC, Ewing PC, van der Burg ME, Stoter G, Nooter K and Berns EM: Molecular profiling of platinum resistant ovarian cancer. Int J Cancer 118: 1963-1971, 2006.

23. Min J, Stegner AL, Alexander H and Alexander S: Overexpression of sphingosine-1-phosphate lyase or inhibition of sphingosine kinase in Dictyostelium discoideum results in a selective increase in sensitivity to platinum-based chemotherapy drugs. Eukaryot Cell 3: 795-805, 2004.
24. Min J, Van Veldhoven PP, Zhang L, Hanigan MH, Alexander H and Alexander S: Sphingosine-1-phosphate lyase regulates sensitivity of human cells to select chemotherapy drugs in a p38-dependent manner. Mol Cancer Res 3: 287-296, 2005.

25. Bonhoure E, Pchejetski D, Aouali N, Morjani H, Levade T, Kohama $\mathrm{T}$ and Cuvillier O: Overcoming MDR-associated chemoresistance in HL-60 acute myeloid leukemia cells by targeting sphingosine kinase-1. Leukemia 20: 95-102, 2006.

26. Pchejetski D, Golzio M, Bonhoure E, Calvet C, Doumerc N, Garcia V, Mazerolles C, Rischmann P, Teissie J, Malavaud B and Cuvillier O: Sphingosine kinase-1 as a chemotherapy sensor in prostate adenocarcinoma cell and mouse models. Cancer Res 65: 11667-11675, 2005 .

27. Alexander S, Min J and Alexander H: Dictyostelium discoideum to human cells: pharmacogenetic studies demonstrate a role for sphingolipids in chemoresistance. Biochim Biophys Acta 1760: 301-309, 2006.

28. Akao Y, Banno Y, Nakagawa Y, Hasegawa N, Kim TJ, Murate T, Igarashi Y and Nozawa Y: High expression of sphingosine kinase 1 and S1P receptors in chemotherapy-resistant prostate cancer PC3 cells and their camptothecin-induced up-regulation. Biochem Biophys Res Commun 342: 1284-1290, 2006.

29. Di NF, Mercer SJ, Knight LA, Gabriel FG, Whitehouse PA, Sharma S, Fernando A, Glaysher S, Di PS, Johnson P, Somers SS, Toh S, Higgins B, Lamont A, Gulliford T, Hurren J, Yiangou C and Cree IA: Cancer cell adaptation to chemotherapy. BMC Cancer 5: 78, 2005.

30. Matsuyama R, Togo S, Shimizu D, Momiyama N, Ishikawa T, Ichikawa Y, Endo I, Kunisaki C, Suzuki H, Hayasizaki Y and Shimada H: Predicting 5-fluorouracil chemosensitivity of liver metastases from colorectal cancer using primary tumor specimens: three-gene expression model predicts clinical response. Int J Cancer 119: 406-413, 2006.

31. Park JS, Young YS, Kim JM, Yeom YI, Kim YS and Kim NS: Identification of novel genes associated with the response to 5-FU treatment in gastric cancer cell lines using a cDNA microarray. Cancer Lett 214: 19-33, 2004.

32. Kaneta Y, Kagami Y, Katagiri T, Tsunoda T, Jin-nai I, Taguchi H, Hirai H, Ohnishi K, Ueda T, Emi N, Tomida A, Tsuruo T, Nakamura Y and Ohno R: Prediction of sensitivity to STI571 among chronic myeloid leukemia patients by genome-wide cDNA microarray analysis. Jpn J Cancer Res 93: 849-856, 2002.

33. Okutsu J, Tsunoda T, Kaneta Y, Katagiri T, Kitahara O, Zembutsu H, Yanagawa R, Miyawaki S, Kuriyama K, Kubota N, Kimura Y, Kubo K, Yagasaki F, Higa T, Taguchi H, Tobita T, Akiyama H, Takeshita A, Wang YH, Motoji T, Ohno R and Nakamura Y: Prediction of chemosensitivity for patients with acute myeloid leukemia, according to expression levels of 28 genes selected by genome-wide complementary DNA microarray analysis. Mol Cancer Ther 1: 1035-1042, 2002.

34. Ochi K, Daigo Y, Katagiri T, Nagayama S, Tsunoda T, Myoui A, Naka N, Araki N, Kudawara I, Ieguchi M, Toyama Y, Toguchida J, Yoshikawa H and Nakamura Y: Prediction of response to neoadjuvant chemotherapy for osteosarcoma by gene-expression profiles. Int J Oncol 24: 647-655, 2004.

35. Lossos IS, Czerwinski DK, Alizadeh AA, Wechser MA, Tibshirani R, Botstein D and Levy R: Prediction of survival in diffuse large-B-cell lymphoma based on the expression of six genes. N Engl J Med 350: 1828-1837, 2004.

36. Ma XJ, Wang Z, Ryan PD, Isakoff SJ, Barmettler A, Fuller A, Muir B, Mohapatra G, Salunga R, Tuggle JT, Tran Y, Tran D, Tassin A, Amon P, Wang W, Wang W, Enright E, Stecker K, Estepa-Sabal E, Smith B, Younger J, Balis U, Michaelson J, Bhan A, Habin K, Baer TM, Brugge J, Haber DA, Erlander MG and Sgroi DC: A two-gene expression ratio predicts clinical outcome in breast cancer patients treated with tamoxifen. Cancer Cell 5: 607-616, 2004.

37. Hoffman RM: In vitro sensitivity assays in cancer: a review, analysis, and prognosis. J Clin Lab Anal 5: 133-143, 1991.

38. Hoffman RM: In vitro assays for chemotherapy sensitivity. Crit Rev Oncol Hematol 15: 99-111, 1993.

39. Ohie S, Udagawa Y, Kozu A, Komuro Y, Aoki D, Nozawa S, Moossa AR and Hoffman RM: Cisplatin sensitivity of ovarian cancer in the histoculture drug response assay correlates to clinical response to combination chemotherapy with cisplatin, doxorubicin and cyclophosphamide. Anticancer Res 20: 2049-2054, 2000. 